\title{
Ruminant and industrial sources of trans-fat and cardiovascular and diabetic diseases
}

\author{
Anne-Laure Tardy ${ }^{1,2,3}$, Béatrice Morio ${ }^{1,2,3 *}$, Jean-Michel Chardigny ${ }^{1,2,3}$ \\ and Corinne Malpuech-Brugère ${ }^{1,2,3}$ \\ ${ }^{1}$ INRA, UMR 1019 Nutrition Humaine, F-63122 Saint Genès Champanelle, France \\ ${ }^{2}$ Clermont Université, UFR Médecine, UMR 1019 Nutrition Humaine, F-63000 Clermont-Ferrand, France \\ ${ }^{3}$ CRNH Auvergne, F-63000 Clermont-Ferrand, France
}

\begin{abstract}
The various positional isomers of oleic acid $(18: 1 \Delta 9 \mathrm{c}$ or $9 \mathrm{c}-18: 1)$ may have distinct biological effects. Detrimental effects of consumption of industrial trans-fatty acids (TFA) (elaidic acid; $18: 1 \Delta 9 \mathrm{t}$ ) from partially hydrogenated vegetable oils on CVD risk factors are well documented. In addition, epidemiological data suggest that chronic consumption of industrial sources of TFA could alter insulin sensitivity and predispose for type 2 diabetes. However, intervention studies on this issue have remained inconclusive. Moreover, very little information is

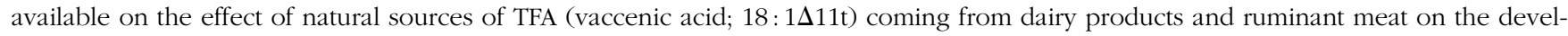
opment of CVD and type 2 diabetes. The review focuses on the impact of the consumption of ruminant TFA in relation to cardiovascular risk factors, inflammation and type 2 diabetes.
\end{abstract}

Key words: Trans-fatty acids: Atherosclerosis: Cholesterol: LDL: CVD: Risk factors: Diabetes

\section{Introduction}

Evidence is now emerging that the incidence of metabolic disorders such as cardiovascular diseases and type 2 diabetes could be affected by dietary fatty acid composition. Among all the dietary lipids, the present review will focus on trans-fatty acids (TFA), since they are the object of a worldwide public health discussion, which requires solid and pertinent metabolic demonstrations in order to promulgate new nutritional recommendations. In fact, food safety authorities need clear, scientifically proven information to further legislate on the subject. TFA are MUFA or PUFA in which the hydrogen atoms are on opposite sides of the fatty acid double bonds, therefore changing their configuration and their chemical properties. TFA represent on average 1 to $2 \%$ of daily energy intake. The main food sources of TFA are partially hydrogenated oil (industrial products) and ruminant-derived foods (dairy products and meat). The isomers of 18:1 (oleic acid, $18: 1 \Delta 9 \mathrm{c}$ or $18: 1 \mathrm{cis}-9$ ) have been found to contribute 54 to $82 \%$ of the total TFA intake ${ }^{(1)}$. The major TFA formed by partial hydrogenation of vegetable oils (industrial TFA;

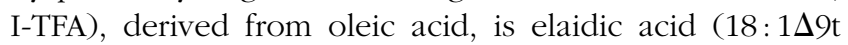
or 18:1 trans-9), whereas the main TFA resulting from rumen biohydrogenation (ruminant-TFA; R-TFA) is vaccenic acid $(18: 1 \Delta 11 \text { t or } 18: 1 \text { trans-11) })^{(2)}$ (Fig. 1). In partial hydrogenation of vegetable oils, the trans-18:1 isomers usually vary from 4 to 16 carbons from a Gaussian distribution that centres about the $\mathrm{d} 9$ or $\mathrm{d} 10$ double bond. The distribution depends first on the starting vegetable oil and second on the extent of hydrogenation. For instance, in mildly hydrogenated soyabean oils, $10 \mathrm{t}-18: 1$ and $11 \mathrm{t}-18: 1$ are the major isomers whereas $9 \mathrm{t}-18: 1$ is the major one in heavily hydrogenated soyabean oil $^{(3)}$. The distribution is different in ruminant fats. The major isomer is always $11 \mathrm{t}-18: 1$, reaching about $70 \%$ of the total trans-18:1, whereas $10 t-18: 1$ and $9 t-18: 1$ appear in small amounts ${ }^{(4)}$.

The R-TFA term comprises total TFA (all the geometrical isomers of MUFA and PUFA) having non-conjugated, carbon-carbon double bonds in the trans configuration, except the conjugated linoleic acids, according to the definition of the French Food Safety Agency (L'Agence française de sécurité sanitaire des aliments; AFSSA, now known as ANSES) $)^{(5)}$. The health effects of both industrial and ruminant sources of TFA are an important issue, since both are widespread ingredients in the food industry. As will be discussed later, the metabolic effects of I-TFA have been widely studied, whereas the impact of R-TFA

Abbreviations: I-TFA, industrial trans-fatty acid; R-TFA, ruminant trans-fatty acid; TEI, total energy intake; TFA, trans-fatty acid.

*Corresponding author: Dr Béatrice Morio, fax +334736082 55, email morio@clermont.inra.fr 


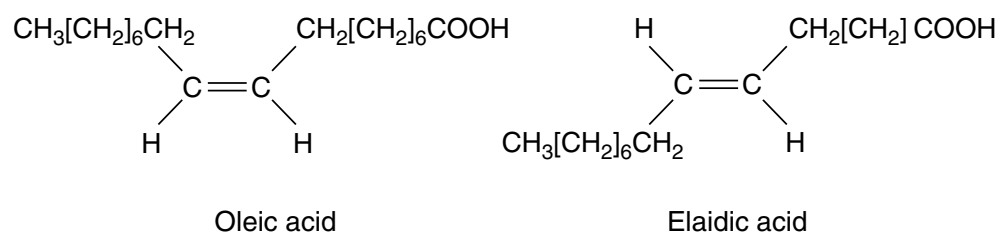

Fig. 1. Cis- and trans-MUFA: 18:1 (n-9) cis or oleic acid, and 18:1 (n-9) trans or elaidic acid, respectively.

has thus far been ignored. Indeed, milk fat contains low amounts of TFA (3-7\% by wt) compared with partially hydrogenated oil (10-60\% by wt), making it difficult to compare their respective effects ${ }^{(6)}$. The study of specific effects of the TFA isomer of ruminant origin has become possible since the discovery that milk fat TFA content can be enhanced by modifying the cows' diet ${ }^{(7)}$. Understanding the specific effect of ruminant-sourced TFA is an important issue for two main reasons. First, in Europe, the contribution of TFA from ruminant fat ranged from about 30 to $80 \%$ of total TFA, corresponding to $0.3-0.8 \%$ of energy $^{(8)}$ and perhaps even more since food safety authorities incite food companies to decrease the amount of industrially sourced TFA in food formula ${ }^{(1,5)}$. Second, the average distribution of R-TFA intake is about $85 \%$ from dairy products and $15 \%$ from ruminant meat ${ }^{(9,10)}$; consequently, the intake of R-TFA is mainly determined by the intake of high-fat dairy products. In fact, the cows' diet is the major environmental factor regulating milk fat composition and many strategies have been developed to reduce medium-chain SFA, for instance fresh pasture modifies the SFA/MUFA-PUFA ratio, decreasing milk fat SFA and enhancing milk fat conjugated linoleic acids and TFA ${ }^{(1,11)}$.

In the present review, to identify the most accurate papers, we used both PubMed databases and ISI Web of Knowledge ${ }^{\mathrm{SM}}$, using 'trans fatty acid' and 'cardiovascular' as keywords leading to 291 hits for the cardiovascular section, where the only inclusion criterion was human; for the diabetes part, 'trans fatty acid' and 'diabetes' were used as keywords, there were no inclusion or exclusion criteria, and 208 hits were recovered.

\section{Trans-fatty acids and cardiovascular risk biomarkers}

\section{Impact of trans-fatty acids on the risk of CHD}

A complete review on the effects of TFA on risks for CVD has been recently published by Micha \& Mozaffarian in $2009^{(12,13)}$. In the present review, we will only focus on the studies that distinguished the origins of the dietary TFA (Table 1).

Few studies investigated the association between the total intake of TFA and the risk of CHD; moreover, to our knowledge, only five studies looked at the association between intake of R-TFA and CHD. Among them, three prospective studies $^{(14-16)}$ and one case-control study ${ }^{(15)}$ showed no significant association between intake of
R-TFA and risk of CHD and one no differences between the different TFA sources ${ }^{(17)}$.

In the Nurses' Health Study, after 20 years of follow-up, total TFA intake was positively associated with CHD risk, as the multivariate relative risk for the highest $v$. the lowest quintile of intake was 1.33 ( $P$ for trend $=0 \cdot 01$ ). However, when these authors did an analysis excluding women who in 1980 reported that their margarine intake had greatly changed in the previous 10 years, after adjustment for established risk factors and dietary lipids, the relative risk (highest $v$. lowest quintile of trans-isomer intake) of CHD with the intake of trans-isomers from animals was $0.59(95 \%$ CI $0.30,1.17 ; P$ for trend=0.230), which means no significant associations between R-TFA intake and the risk of $\mathrm{CHD}^{(14)}$.

In a case-control study conducted in the Boston area (MA, USA) with both men and women aged about 57 years, Ascherio et al. ${ }^{(15)}$ observed no significant association between the intake of trans-isomers from animal fats (R-TFA) (about $0.7 \%$ of energy in the highest quintile) and myocardial infarction: relative risk adjusted for established risk factors, dietary lipids and energy was 1.02 (95\% CI 0.43, 2.41; $P$ for trend=0.57).

Recently, results obtained from 3686 men and women from four Danish cohort studies ${ }^{(16)}$ suggest that an intake of R-TFA of about $1.1 \%$ of total energy intake (TEI) (about $2.7 \mathrm{~g} / \mathrm{d}$ for women and $3.4 \mathrm{~g} / \mathrm{d}$ for men in the highest quintile) is not associated with a higher risk of CVD. No evidence of a higher risk associated with R-TFA intake within the wide range of intake among both women (90\% central range: $0 \cdot 5-3 \cdot 1 \mathrm{~g} / \mathrm{d})$ and men (90\% central range: $0 \cdot 6-4 \cdot 1 \mathrm{~g} / \mathrm{d}$ ) was found.

Moreover, in the Alpha-Tocopherol, Beta-Carotene Cancer Prevention Study, which was a randomised, double-blind, placebo-controlled primary prevention trial, 21930 men (aged 50-69 years) followed-up for 5-8 (median 6.1) years were analysed ${ }^{(18)}$. Men were grouped into quintiles of energy-adjusted intakes of nutrients as calculated from the dietary questionnaire. No association was reported between coronary death and dietary intake of TFA of animal origin ( $P$ for trend=0.857). The relative risk of coronary death after adjustment for age, smoking, BMI, blood pressure, intakes of energy, alcohol, and fibre, education $(<7,7-11,>11$ years $)$ and physical activity $(<1,1-$ $2,>2$ times per week) was $0.83(95 \%$ CI $0.62,1.11)$ ( $P$ for trend $=0.035)$ for animal TFA for the highest $(2.5 \mathrm{~g}$, about 
Table 1. Effect of industrial and ruminant trans-fatty acids (TFA) on CVD (adapted from Booker \& Mann $\left.{ }^{(35)}\right)^{*}$

\begin{tabular}{|c|c|c|c|c|c|c|c|c|}
\hline \multirow[b]{2}{*}{ Marker } & \multirow[b]{2}{*}{ Subjects and cases } & \multirow[b]{2}{*}{ TFA origin } & \multicolumn{5}{|c|}{ Intake grouping } & \multirow{2}{*}{$\begin{array}{l}P \text { for trend } \\
\text { across groupings }\end{array}$} \\
\hline & & & 1 (lowest) & 2 & 3 & 4 & 5 (highest) & \\
\hline \multicolumn{9}{|c|}{ Nurses' Health Study(14): isomers from animal (R-TFA) and vegetable fat (I-TFA) } \\
\hline \multirow[t]{4}{*}{ CHD incidence } & 69181 women 356 cases & R-TFA intake (\% TEI) & $0.43 \%$ TEI & $0.58 \%$ TEI & $0.70 \%$ TEI & $0.81 \%$ TEI & $1.03 \%$ TEI & 0.230 \\
\hline & & $\mathrm{RR}$ & 1 & $0.76(0.51,1.12)$ & $0.69(0.43,1.10)$ & $0.55(0.31,0.96)$ & $0.59(0.30,1.17)$ & \\
\hline & & I-TFA intake (\% TEI) & $0.65 \% \mathrm{TEI}$ & $0.86 \%$ TEl & $1.05 \% \mathrm{TEl}$ & $1.22 \% \mathrm{TEI}$ & $1.54 \%$ TEI & 0.009 \\
\hline & & $\mathrm{RR}$ & 1 & $1.43(1.00,2.04)$ & $1.11(0.74,1.66)$ & $1.39(0.91,2.13)$ & $1.78(1 \cdot 12,2 \cdot 83)$ & \\
\hline \multicolumn{9}{|c|}{ Zutphen Elderly Cohort Study ${ }^{(17)}$ : total TFA: R-TFA and manufactured 18:1 TFA } \\
\hline \multirow[t]{2}{*}{ CHD incidence } & 667 men & R-TFA intake (\% TEI) & $2.36 \%$ TEI & $3.87 \%$ TEI & $6.38 \%$ TEI & & & 0.003 \\
\hline & 98 events & $\mathrm{RR}$ & 1.0 & $1.34(0.78,2.37)$ & $2.00(2.07,3.75)$ & & & \\
\hline \multicolumn{9}{|c|}{ Alpha-Tocopherol, Beta-Carotene Study ${ }^{(18)}$ : total TFA, animal TFA (R-TFA) and elaidic acid $(18: 1 \Delta 9 \mathrm{t}) \dagger$} \\
\hline \multirow{6}{*}{\multicolumn{2}{|c|}{ Coronary death $\quad 21930$ men 635 cases }} & Total TFA intake (\% TEI) & $0.81 \%$ TEl & $1.08 \%$ TEI & $1.31 \%$ TEI & $1.58 \%$ TEI & $2.79 \%$ TEI & 0.004 \\
\hline & & RR & 1.00 & $1.05(0.81,1.36)$ & $1.12(0.87,1.45)$ & $0.90(0.59,1.18)$ & $1.39(1.09,1.78)$ & \\
\hline & & R-TFA intake (\% TEI) & $0.27 \%$ TEl & $0.50 \% \mathrm{TEI}$ & $0.68 \% \mathrm{TEI}$ & $0.86 \% \mathrm{TEI}$ & $1.13 \% \mathrm{TEI}$ & 0.035 \\
\hline & & $\mathrm{RR}$ & 1.00 & $0.97(0.75,1.25)$ & $0.91(0.70,1.19)$ & $0.90(0.69,1.17)$ & $0.83(0.62,1.11)$ & \\
\hline & & $18: 1 \Delta 9 \mathrm{t}$ intake $(\% \mathrm{TEI})$ & $0.59 \%$ TEI & $0.77 \%$ TEl & $0.90 \% \mathrm{TEl}$ & $1.22 \%$ TEI & $2.52 \%$ TEl & 0.02 \\
\hline & & RR & 1.00 & $1.03(0.80,1.34)$ & $1.04(0.80,1.34)$ & $0.90(0.69,1.18)$ & $1.37(1.07,1.75)$ & \\
\hline \multicolumn{9}{|c|}{ Scottish Heart Health Study ${ }^{(19)}$ : I-TFA and R-TFA } \\
\hline \multirow{8}{*}{$\begin{array}{l}\text { CHD (angina and/or } \\
\text { myocardial infarction) }\end{array}$} & 4490 men 369 cases & R-TFA intake (\% TEI) & $0.68 \% \mathrm{TEl}$ & $0.99 \% \mathrm{TEl}$ & $1 \cdot 26 \%$ TEI & $1.53 \% \mathrm{TEI}$ & $2 \cdot 21 \%$ TEI & 0.79 \\
\hline & & OR & 1 & $0.74(0.50,1.11)$ & $0.75(0.48,1.17)$ & $0.81(0.48,1.39)$ & $1.53(0.75,3.11)$ & \\
\hline & & I-TFA intake (\% TEI) & $0.45 \% \mathrm{TEI}$ & $1.08 \% \mathrm{TEI}$ & $1.67 \% \mathrm{TEI}$ & $2.30 \% \mathrm{TEI}$ & $3.96 \%$ TEI & 0.03 \\
\hline & & OR & 1 & $0.65(0.45,0.95)$ & $0.88(0.61,1.27)$ & $0.62(0.41,0.93)$ & $0.58(0.37,0.91)$ & \\
\hline & 5170 women 235 cases & R-TFA intake (\% TEI) & $0.54 \%$ TEI & $0.86 \%$ TEI & $1.08 \% \mathrm{TEI}$ & $1.35 \%$ TEI & $1.94 \%$ TEI & 0.27 \\
\hline & & OR & 1 & $1.03(0.64,1.67)$ & $0.80(0.46,1.39)$ & $0.74(0.40,1.40)$ & $0.71(0.30,1.70)$ & \\
\hline & & I-TFA intake (\% TEI) & $0.41 \% \mathrm{TEI}$ & $1.08 \%$ TEI & $1.58 \% \mathrm{TEI}$ & $2.21 \% \mathrm{TEI}$ & $3.74 \%$ TEI & 0.52 \\
\hline & & OR & 1 & $0.82(0.52,1.28)$ & $0.59(0.35,0.97)$ & $0.81(0.49,1.34)$ & $0.84(0.49,1.45)$ & \\
\hline \multicolumn{9}{|c|}{ Study from four Danish cohorts ${ }^{(16)}$ : R-TFA } \\
\hline \multirow[t]{4}{*}{ CHD events } & 1837 men 253 cases & R-TFA intake (\% TEI) & $0.36 \% \mathrm{TEI}$ & $0.59 \%$ TEI & $0.81 \%$ TEI & $1.08 \% \mathrm{TEI}$ & $1.37 \%$ TEI & \\
\hline & & Number of events & & & & & & $>0.05$ \\
\hline & 1849 women 121 cases & R-TFA intake (\% TEI) & $0.32 \%$ TEI & $0.50 \%$ TEI & $0.68 \%$ TEI & $0.86 \%$ TEI & $1.22 \%$ TEI & \\
\hline & & Number of events & 27 & 28 & 16 & 22 & 28 & $>0.05$ \\
\hline
\end{tabular}

R-TFA, ruminant TFA; I-TFA, industrial TFA; TEl, total daily energy intake estimated as $2000 \mathrm{kcal} / \mathrm{d}$ (8370 kJ/d); RR, relative risk.

*Values are expressed as RR $(95 \% \mathrm{Cl})$ except for the Scottish Heart Health Study, where they are expressed as OR $(95 \% \mathrm{CI})$, and the study from four Danish cohorts, where they are expressed as number of events. $\dagger$ Adjusted for age, treatment group, smoking, BMI, blood pressure, intakes of energy, alcohol and fibre, education and physical activities.
f Adjusted for age, weight, height, smoking, physical activity, diastolic pressure, TEl, intakes of SFA, linoleic acid and antioxidant vitamins. 
$33 \%$ of total TFA intake) compared with the lowest $\left(0.6 \mathrm{~g} / \mathrm{d}\right.$, about $33 \%$ of total TFA) quintile ${ }^{(18)}$.

Only Oomen et al. ${ }^{(17)}$ found a similar effect between the different TFA sources. Indeed, in their prospective population-based study, 667 men of the Zutphen Elderly Study aged 64-84 years and free of $\mathrm{CHD}$ at baseline were studied. Dietary surveys were used to establish the participants' food consumption patterns ${ }^{(17)}$. The relative risks of CHD for an increase of $0.5 \%$ in energy at baseline from TFA from different sources (R-TFA, manufactured 18:1 TFA and other manufactured TFA) was calculated. For a mean intake of 0.7 (SD 0.2 ) \% of energy (about $1.22 \mathrm{~g} / \mathrm{d}$ with TEI at $9 \cdot 2 \mathrm{MJ})$ the relative risk was $1.17(95 \% \mathrm{CI}$ $0.69,1.98)$ and was similar to the others $\mathrm{TFA}^{(17)}$. It is important to note that during the follow-up, the food items have varied and the amount of TFA has decreased. For instance, after 10 years of follow-up, the mean contribution of TFA intake to TEI decreased from 1985 to 1990 and $1995(4.3(\mathrm{SD} 2.2) v .2 .9(\mathrm{SD} \mathrm{1.5)} v .1 .9$ (SD 0.6)\%).

\section{Impact of trans-fatty acids on markers of CHD}

Effects of trans-fatty acids on HDL- and LDL-cholesterol. The story linking ruminant TFA intake or biomarkers of TFA intake with the serum lipid profile began about 15 years ago when Bolton-Smith et al. demonstrated that in between 4490 and 5170, respectively, for men and women, the total cholesterol varied significantly $(P<0.001)$ by fifths of the R-TFA for men $(1.5$ to $4.9 \mathrm{~g}$ $\mathrm{R}-\mathrm{TFA} / \mathrm{d}$ from the lowest to the highest fifths) and women ( 1.2 to $4.3 \mathrm{~g}$ R-TFA/d from the lowest to the highest fifths) (positive trend) and by fifths of I-TFA for men (1 to $8.8 \mathrm{~g} \mathrm{I-TFA} / \mathrm{d}$ from the lowest to the highest fifths) (negative trend) who participated in the Scottish Heart Health Study ${ }^{(19)}$.

Recently, Chardigny et al. ${ }^{(20)}$ compared the effects of an 8 weeks consumption of $5 \cdot 4 \%$ of TEI (about $11-12 \mathrm{~g} / \mathrm{d}$ ) as TFA from hydrogenated sources with the same amount of TFA from ruminant sources on lipoprotein metabolism in forty-six healthy men and women. This study was a monocentric, randomised, double blind, controlled, cross-over design. In women, but not in men, R-TFA beneficially increased HDL-cholesterol concentrations. However, an increase in LDL-cholesterol and TAG concentrations was also observed. For both sexes, the serum total cholesterol: HDL-cholesterol ratio did not change. In a second study published at the same time by Motard-Bélanger et al. ${ }^{(21)}$, the effects of TFA from ruminant sources were studied in a double-blind, randomised, cross-over controlled study according to a Latin square design, in which each man was assigned to four different isoenergetic diets lasting 4 weeks each. In this study, diets were high in R-TFA $(10 \cdot 2 \mathrm{~g} / 2500 \mathrm{kcal}(10460 \mathrm{~kJ}) ; 3.7 \%$ of TEI), moderate in R-TFA $(4.2 \mathrm{~g} / 2500 \mathrm{kcal} ; 1.5 \%$ of TEI), high in I-TFA $(10 \cdot 2 \mathrm{~g} / 2500 \mathrm{kcal})$, or low in TFA from any source $(2 \cdot 2 \mathrm{~g} /$ $2500 \mathrm{kcal})$ (control diet). It was found that at high intakes
(3.7\% of TEI), TFA from both ruminant and hydrogenated sources adversely affected cholesterol metabolism. At intakes of $1.5 \%$ of TEI, no effects of TFA from ruminant sources on the serum lipoprotein profile were observed.

Relationship between trans-fatty acids and markers of haemostatic function. The story of the relationship between TFA intake and cardiovascular risk factors continues with the study of the effects of TFA on markers for platelet aggregation, coagulation and fibrinolysis, three main determinants of haemostatic function.

Tholstrup et $a l^{(22)}$ demonstrated no adverse effect of a daily intake of $3.5 \mathrm{~g}$ (about $1 \%$ of TEI) of vaccenic acid (18: $1 \Delta 11 \mathrm{t}$ ) from enriched butter during 5 weeks on haemostatic risk markers (plasminogen activator inhibitor 1 and factor FVII coagulant activity) of forty-two healthy young men, compared with a control butter that provided $0 \cdot 3 \mathrm{~g}$ vaccenic acid per $\mathrm{d}(18: 1 \Delta 11 \mathrm{t})^{(22)}$. However, the authors concluded that these effects may have been partly attributable to the higher MUFA and lower SFA content of the high-vaccenic acid $(18: 1 \Delta 11 \mathrm{t})$ diet, rather than to the effects of vaccenic acid $(18: 1 \Delta 11 \mathrm{t})$ itself.

The consumption of a diet rich in vaccenic acid (18: $1 \Delta 11 \mathrm{t}$ ) (about $3.5 \mathrm{~g} / \mathrm{d}$; about $1 \%$ TEI) for 5 weeks did not adversely affect blood pressure or isobaric arterial elasticity when measured in healthy young men by a volume-oscillometric method $^{(23)}$. These authors compared the effect of a diet based on milk fat high in vaccenic acid $(18: 1 \Delta 11 \mathrm{t})$, and not vaccenic acid (18: $1 \Delta 11 \mathrm{t})$ per se.

Relationship between trans-fatty acids and markers of inflammation and endothelial dysfunction. Markers of inflammation have been implicated as risk factors for several degenerative diseases. With respect to CVD, the data collected from cross-sectional and prospective studies provide evidence that some markers are independent risk factors, and several of them can be modifiable throughout lifestyle, by physical exercise, smoking and also diet.

No observational studies have reported a correlation between a high content of R-TFA and biomarkers of inflammation in healthy volunteers, and only a few interventional studies have followed the effect of the consumption of R-TFA on inflammatory parameters.

Kuhnt et $a l .{ }^{(24)}$ designed a study to investigate the effects of a 6 -week dietary supplementation of $3 \mathrm{~g}$ of vaccenic acid $(18: 1 \Delta 11 \mathrm{t})$ and $3 \mathrm{~g}$ of $18: 1 \Delta 12 \mathrm{t}$ and endogenous conjugated linoleic acid synthesis on several biomarkers (IL-6 and IL-8, TNF- $\alpha$, C-reactive protein, inter-cellular adhesion molecule-1, leptin and adiponectin) in young men and women. These markers belong to the systemic inflammation which has been reported as an independent risk factor for heart disease ${ }^{(25)}$. No significant differences in the plasma concentrations of any biomarker were observed during the $18: 1 \Delta 11 \mathrm{t}$ and $18: 1 \Delta 12 \mathrm{t}$ intervention; these results were in agreement with the results of Thosltrup et al. ${ }^{(22)}$.

In healthy men, Motard-Belanger et al. ${ }^{(21)}$ found that the circulating level of C-reactive protein was not statistically 
different at the end of 4 weeks of experimental isoenergetic diets high in ruminant or industrial TFA $(10 \cdot 2 \mathrm{~g} / 2500 \mathrm{kcal}$ $(10460 \mathrm{~kJ})$ ). In our study published in 2008 , we found no effect of consumption for 4 weeks of food items containing TFA $(11-12 \mathrm{~g} / \mathrm{d})$ from ruminants and from industrial sources on the plasma high-sensitivity C-reactive protein concentration of forty-six healthy subjects ${ }^{(26)}$.

These different results on the effects of the intake of R-TFA on the development of cardiovascular pathologies are still contradictory, even though they tend to underline isomer-specific effects. Weggemans et al. ${ }^{(27)}$ concluded that epidemiological studies from Europe and the USA show that up to $2.5 \mathrm{~g} / \mathrm{d}$, the effects of total, ruminant or industrial TFA are similar. An intake of more than $3 \mathrm{~g} / \mathrm{d}$ of total and industrial TFA is associated with increased CHD risk. However, there are insufficient data on the health effects of ruminant TFA intakes over $2.5 \mathrm{~g} / \mathrm{d}$ to allow any comparison in this range. They therefore advised not to discriminate between these sources in legislation or dietary recommendations. However, recently, Jakobsen et al. ${ }^{(16)}$, using data from the four Danish cohort studies, found no evidence of a higher risk associated with R-TFA intake within the wide range of intake among both women (90\% central range: $0 \cdot 5-3 \cdot 1 \mathrm{~g} / \mathrm{d}$ ) and men (90\% central range: $0 \cdot 6-4 \cdot 1 \mathrm{~g} / \mathrm{d})$. The authors concluded that a high intake of TFA from dairy and ruminant meat products is an issue of no concern to public health.

\section{Trans-fatty acids and risks for type 2 diabetes}

Type 2 diabetes is characterised by an increased blood glucose level due to impaired insulin sensitivity by peripheral tissues and decreased insulin secretion by pancreatic $\beta$-cells.

Effects of trans-fatty acids on glucose tolerance and type 2 diabetes

An important body of evidence relating total TFA intake to risk of type 2 diabetes came from the Nurses' Health Study that prospectively followed, during 14 years, 84204 healthy women aged between 34 and 59 years $^{(28)}$. The data suggested that total lipid intake, compared with equivalent energy intake from carbohydrates, was not associated with the risk of type 2 diabetes in women. By contrast, the study reported that high intakes of TFA (3 (SD 0.5$) \%$ of total daily energy intake, TEI) correlated positively with the risk of diabetes in age- and BMI-adjusted analyses. In addition, the authors estimated that replacing $2 \%$ of energy from TFA isoenergetically with PUFA would lead to a $40 \%$ lower risk of developing type 2 diabetes. Subgroup analyses revealed that effects were primarily observed in obese women, possibly due to the fact that these women were already more insulin resistant than non-obese women $^{(28)}$. In addition, the Nurses' Health Study carried certain methodological limitations that may have affected the interpretation of TFA data. Notably, averaged food composition changed substantially over the 20-year experimental follow-up, in particular with regards to trans-fat content. In addition, foods rich in TFA were also rich in refined carbohydrates. Finally, and most tellingly, the techniques used to assess trans-fat content in foods have also improved $^{(29)}$. In the epidemiological studies, the sources of TFA were not examined, so no conclusions could be brought regarding the respective effects of dairy and hydrogenated fats. In fact, differences in the relative abundance of each TFA isomer in food products could probably lead to different metabolic responses.

Short-term intervention studies in clinical or in animal models have not been very conclusive either. More recently, new data were obtained on the effects of TFA of dairy origin since it is now possible to produce experimental dairy vaccenic acid-enriched fat. A 5-week nutritional double-blind, randomised, parallel intervention study was performed in forty-two healthy young men stratified according to BMI $\left(\mathrm{kg} / \mathrm{m}^{2}\right)$. The volunteers received either a diet high in vaccenic acid $(3.5 \mathrm{~g} / \mathrm{d}$; about $1 \%$ of TEI; $18: 1 \Delta 11 \mathrm{t}$ ) or a control diet providing $0.3 \mathrm{~g}$ vaccenic acid per $\mathrm{d}(18: 1 \Delta 11 \mathrm{t})$. The authors did not find any effects of vaccenic acid-rich dairy fat on fasting insulin and glucose ${ }^{(22)}$.

In rat models, insulin and glucose responses to an intraperitoneal injection of glucose were not modified after 8 weeks of experimental diets enriched in TFA of either dairy or industrial origin at $4 \cdot 1 \%$ of total $\mathrm{TEI}^{(30)}$. These data were reinforced by recent findings by Wang et al., given that, after 4 weeks of a control diet supplemented with $1.5 \%(\mathrm{w} / \mathrm{w})$ vaccenic acid $(18: 1 \Delta 11 \mathrm{t})$, insulin and glucose metabolism of both lean and obese rats was not affected in response to a meal tolerance test ${ }^{(31)}$.

\section{Effects of trans-fatty acids on insulin secretion by pancreatic $\beta$-cells}

Long-term exposure of $\beta$-cells to high levels of fatty acids causes enhanced insulin secretion at low glucose (basal insulin release), while glucose-stimulated insulin secretion is decreased or unchanged. In isolated mouse islets, an acute incubation with the trans isomers trans-vaccenic $(18: 1 \Delta 11 \mathrm{t})$ and elaidic $(18: 1 \Delta 9 \mathrm{t})$ acids elicited a higher maximal insulin output than the cis isomer oleic acid ${ }^{(32)}$ The same authors compared in cultured INS-1 cells the effect of $3 \mathrm{~d}$ incubation with cis- (cis-18:1-11) and trans-vaccenic acid (trans-18:1-11), as well as oleic (cis-18:1-9) and trans-elaidic acid (trans-18:1-9), on basal and glucose-stimulated insulin secretion. All fatty acids tested increased basal insulin release; however, a significantly lower basal insulin release was demonstrated for cells cultured with 0.3 to $0.4 \mathrm{~mm}$-trans-vaccenic acid compared with equimolar levels of the cis isomer. Glucosestimulated insulin secretion was not changed by cis- or trans-vaccenic acid or by oleic acid, whereas it was stimulated by 0.3 to $0 \cdot 4 \mathrm{~mm}$-trans-elaidic acid $^{(33)}$. Despite these 
in vitro results, there are no available data on the impact of TFA of dairy origin on insulin secretion in vivo.

\section{Effects of trans-fatty acids on peripheral insulin sensitivity}

Little is known on the effects of TFA of both origins on insulin sensitivity in humans. An important step towards glucose intolerance and type 2 diabetes is peripheral resistance to insulin action.

A 4-week nutritional double-blind, randomised, parallel intervention study was performed in sixty-three healthy women with abdominal obesity (waist circumference $>88$ $\mathrm{cm}$ and $\mathrm{BMI}>28 \mathrm{~kg} / \mathrm{m}^{2}$ ). After a run-in period, the volunteers were randomly assigned to consume for 4 weeks one of the three following diets: $60 \mathrm{~g}$ low-TFA lipids/d $(0.54 \mathrm{~g} / \mathrm{d} ; n$ 21), R-TFA-rich lipids $(4.86 \mathrm{~g} / \mathrm{d} ; n$ 21), or I-TFA-rich lipids $(5.58 \mathrm{~g} / \mathrm{d} ; n$ 21). Changes in peripheral insulin sensitivity were assessed by using hyperinsulinaemic-euglycaemic clamps. The results showed that TFA from dairy and industrial sources ingested at a nutritional level ( $2 \%$ of total TEI) for 4 weeks do not further alter peripheral insulin sensitivity in overweight and obese women with impaired insulin sensitivity ${ }^{(26)}$. However, the principle of precaution required that these results are not extended to long-term effects of TFA.

To go further in the comprehension of the mechanisms, Tardy et al. established in C2C12 myotubes that insulinstimulated Akt phosphorylation was similar to the control group (without fatty acid) after incubation with oleic, elaidic and vaccenic acids ${ }^{(30)}$, suggesting no direct effect of TFA on muscle insulin pathways. Those results were reinforced by a recent study of Hommelberg et al. ${ }^{(34)}$ which demonstrated in cultured murine skeletal muscle cells that insulin-stimulated glucose uptake and GLUT4 translocation were similar to those in the control group after incubation with vaccenic and elaidic acids.

In addition, Tardy et al. also demonstrated that oxidative (soleus) and glycolytic (tibialis anterior) muscle mitochondria have the same capacity to oxidise cis-fatty acids and TFA (elaidic and vaccenic acids), suggesting that the geometrical MUFA configuration does not heavily influence their oxidation rate. Thus, any TFA-induced alteration in muscle metabolism is not due to differences in oxidation rates ${ }^{(30)}$.

To conclude, there is a body of evidence showing an absence of TFA effects on skeletal muscle insulin sensitivity. However, additional studies are required, especially on adipose tissue, to further analyse metabolic responses to TFA, including bioenergetic, lipid and carbohydrate pathways

\section{Conclusion}

While TFA from hydrogenated oils have been clearly implicated in the pathogenesis of CVD, those from dairy products may be less deleterious at a level lower than $2 \%$ of total TEI. Furthermore, dietary intakes of TFA from dairy origin are far from being high enough to constitute a serious threat for public health. As concluded by Booker \& Mann ${ }^{(35)}$, the advice would be to remove TFA from industrial sources from the food supply. Therefore, regular moderate consumption of dairy fats could be tolerated with respect to cardiovascular risks. Regarding the role of TFA from both origins on the incidence of type 2 diabetes, studies carried out on the topic are still controversial. Combined results suggest that TFA of dairy (R-TFA) and industrial (I-TFA) origins may not impair glucose tolerance at a physiological dose and during a short-term period. Mechanistic and intervention studies showed no significant effect of TFA on glucose tolerance or insulin resistance, suggesting that these fatty acids may not increase the risk for diabetes. The synthesis of these studies does confirm the food safety authority recommendations that their intake should be limited to $2 \%$ of total TEI. Additional data are required to better understand possible long-term effect of TFA, especially to examine the impact of TFA in individuals at risk for the metabolic syndrome and type 2 diabetes.

\section{Acknowledgements}

The present review was supported by the 'ANR - Agence Nationale de la Recherche - The French National Research Agency' under the 'Programme National de Recherche en Alimentation et Nutrition Humaine', project 'ANR-05PNRA-no. 5.E.24'.

All authors have equally contributed to the review; however, C. M.-B. and J.-M. C. wrote together the cardiovascular section and A.-L. T. and B. M. wrote together the diabetes section. A.-L. T. produced Table 1.

There are no conflicts of interest to declare.

\section{References}

1. Scientific Panel on Dietetic Products NaA (2004) Opinion of the Scientific Panel on Dietetic Products, Nutrition and Allergies on a request from the Commission related to the presence of trans fatty acids in foods and the effect on human health of the consumption of trans fatty acids (Request no. EFSA-Q-2003-022). In EFSA Journal, vol. 81, pp. 1-49. Parma, Italy: European Food Safety Authority.

2. Bauman DE, Mather IH, Wall RJ, et al. (2006) Major advances associated with the biosynthesis of milk. J Dairy Sci 89 , $1235-1243$.

3. Wolff RL \& Sebedio JL (1991) Geometrical isomers of linolenic acids in low-caloric spreads marketed in France. J Am Oil Chem Soc 68, 719-725.

4. Ratnayake WM (2004) Overview of methods for the determination of trans fatty acids by gas chromatography, silver-ion thin-layer chromatography, silver-ion liquid chromatography, and gas chromatography/mass spectrometry. $J$ AOAC Int 87, 523-539.

5. Leger C-L \& Razanamahefa L (2005) Risques et bénéfices pour la santé des acides gras trans apportés par les aliments. Recommandations (Risks and Benefits of Food Trans Fatty 
Acids for Human Health. Recommendations). Maison-Alfort: AFSSA.

6. Jensen RG (2002) The composition of bovine milk lipids: January 1995 to December 2000. J Dairy Sci 85, 295-350.

7. Bauman DE \& Griinari JM (2003) Nutritional regulation of milk fat synthesis. Annu Rev Nutr 23, 203-227.

8. Hulshof KF, van Erp-Baart MA, Anttolainen M, et al. (1999) Intake of fatty acids in western Europe with emphasis on trans fatty acids: the TRANSFAIR Study. Eur J Clin Nutr $\mathbf{5 3}$, 143-157.

9. Chilliard Y, Ferlay A, Mansbridge RM, et al. (2000) Ruminant milk fat plasticity: nutritional control of saturated, polyunsaurated, trans and conjugated fatty acids. Ann Zootech 49 , 181-205.

10. Chilliard Y \& Ferlay A (2004) Dietary lipids and forages interactions on cow and goat milk fatty acid composition and sensory properties. Reprod Nutr Dev 44, 467-492.

11. Jakobsen MU, Bysted A, Andersen NL, et al. (2006) Intake of ruminant trans fatty acids in the Danish population aged 1-80 years. Eur J Clin Nutr 60, 312-318.

12. Micha R \& Mozaffarian D (2009) Trans fatty acids: effects on metabolic syndrome, heart disease and diabetes. Nat Rev Endocrinol 5, 335-344.

13. Micha R \& Mozaffarian D (2008) Trans fatty acids: effects on cardiometabolic health and implications for policy. Prostaglandins Leukot Essent Fatty Acids 79, 147-152.

14. Willett WC, Stampfer MJ, Manson JE, et al. (1993) Intake of trans fatty acids and risk of coronary heart disease among women. Lancet 341, 581-585.

15. Ascherio A, Hennekens CH, Buring JE, et al. (1994) Transfatty acids intake and risk of myocardial infarction. Circulation 89, 94-101.

16. Jakobsen MU, Overvad K, Dyerberg J, et al. (2008) Intake of ruminant trans fatty acids and risk of coronary heart disease. Int J Epidemiol 37, 173-182.

17. Oomen CM, Ocke MC, Feskens EJ, et al. (2001) Association between trans fatty acid intake and 10-year risk of coronary heart disease in the Zutphen Elderly Study: a prospective population-based study. Lancet 357, 746-751.

18. Pietinen P, Ascherio A, Korhonen P, et al. (1997) Intake of fatty acids and risk of coronary heart disease in a cohort of Finnish men. The Alpha-Tocopherol, Beta-Carotene Cancer Prevention Study. Am J Epidemiol 145, 876-887.

19. Bolton-Smith C, Woodward M, Fenton S, et al. (1996) Does dietary trans fatty acid intake relate to the prevalence of coronary heart disease in Scotland? Eur Heart J 17, 837-845.

20. Chardigny JM, Destaillats F, Malpuech-Brugere C, et al. (2008) Do trans fatty acids from industrially produced sources and from natural sources have the same effect on cardiovascular disease risk factors in healthy subjects? Results of the Trans Fatty Acids Collaboration (TRANSFACT) study. Am J Clin Nutr 87, 558-566.

21. Motard-Bélanger A, Charest A, Grenier G, et al. (2008) Study of the effect of trans fatty acids from ruminants on blood lipids and other risk factors for cardiovascular disease. $A m$ J Clin Nutr 87, 593-599.

22. Tholstrup T, Raff M, Basu S, et al. (2006) Effects of butter high in ruminant trans and monounsaturated fatty acids on lipoproteins, incorporation of fatty acids into lipid classes, plasma C-reactive protein, oxidative stress, hemostatic variables, and insulin in healthy young men. Am J Clin Nutr 83, $237-243$.

23. Raff M, Tholstrup T, Sejrsen K, et al. (2006) Diets rich in conjugated linoleic acid and vaccenic acid have no effect on blood pressure and isobaric arterial elasticity in healthy young men. J Nutr 136, 992-997.

24. Kuhnt K, Kraft J, Vogelsang H, et al. (2007) Dietary supplementation with trans-11- and trans-12-181 increases cis-9, trans-11-conjugated linoleic acid in human immune cells, but without effects on biomarkers of immune function and inflammation. Br J Nutr 97, 1196-1205.

25. Libby P (2002) Inflammation in atherosclerosis. Nature $\mathbf{4 2 0}$, 868-874.

26. Tardy AL, Lambert-Porcheron S, Malpuech-Brugere C, et al. (2009) Dairy and industrial sources of trans fat do not impair peripheral insulin sensitivity in overweight women. Am J Clin Nutr 90, 88-94.

27. Weggemans RM, Rudrum M \& Trautwein EA (2004) Intake of ruminant versus industrial trans fatty acids and risk of coronary heart disease - what is the evidence? Eur J Lipid Sci Technol 106, 390-397.

28. Salmeron J, Hu FB, Manson JE, et al. (2001) Dietary fat intake and risk of type 2 diabetes in women. Am J Clin Nutr 73, 1019-1026.

29. Clandinin MT \& Wilke MS (2001) Do trans fatty acids increase the incidence of type 2 diabetes? Am J Clin Nutr 73, 1001-1002.

30. Tardy A-L, Giraudet C, Rousset P, et al. (2008) Effects of trans MUFA from dairy and industrial sources on muscle mitochondrial function and insulin sensitivity. J Lipid Res 49 , 1445-1455.

31. Wang Y, Lu J, Ruth MR, et al. (2008) Trans-11 vaccenic acid dietary supplementation induces hypolipidemic effects in JCR:LA-cp rats. J Nutr 138, 2117-2122.

32. Alstrup KK, Gregersen S, Jensen HM, et al. (1999) Differential effects of cis and trans fatty acids on insulin release from isolated mouse islets. Metabolism 48, 22-29.

33. Alstrup KK, Brock B \& Hermansen K (2004) Long-term exposure of INS-1 cells to cis and trans fatty acids influences insulin release and fatty acid oxidation differentially. Metabolism 53, 1158-1165.

34. Hommelberg PP, Langen RC, Schols AM, et al. (2010) Trans fatty acid-induced NF- $\kappa \mathrm{B}$ activation does not induce insulin resistance in cultured murine skeletal muscle cells. Lipids 45, 285-290.

35. Booker CS \& Mann JI (2008) Trans fatty acids and cardiovascular health: translation of the evidence base. Nutr Metab Cardiovasc Dis 18, 448-456. 